eCommons@AKU

January 2014

\title{
Complementary and alternative medicine in oncology nursing
}

Salima Somani

University of Central Asia, Kyrgyz Republic

Fauziya Ali

The Aga khan University, fauziya.ali@aku.edu

Tazeen S. Ali

Aga Khan University, tazeen.ali@aku.edu

Nasreen Sulaiman Lalani

University of Alberta, Canada

Follow this and additional works at: https://ecommons.aku.edu/pakistan_fhs_son

Part of the Nursing Midwifery Commons

\section{Recommended Citation}

Somani, S., Ali, F., Ali, T. S., Lalani, N. S. (2014). Complementary and alternative medicine in oncology nursing. British Journal of Nursing, 23(1), 40-46.

Available at: https://ecommons.aku.edu/pakistan_fhs_son/180 


\section{Abstract}

Use of Complementary and Alternative Medicine (CAM) has increased globally particularly among oncology patients. This study investigated the knowledge, experience and attitudes of oncology nurses towards CAM. A quantitative study was conducted in tertiary care hospitals in Karachi, Pakistan where 132 oncology nurses were surveyed. The survey revealed that more than $50 \%$ of nurses had never heard about many of the CAM therapies used in Pakistan. Approximately $65 \%$ of the nurses had knowledge about prayer and less than $30 \%$ of the nurses had experience of CAM education or training. In addition, the majority of nurses had seen patients using CAM and felt that the health care status could be enhanced with the use of CAM. This study showed that oncology nurses had a positive experience and attitudes towards CAM, although they needed to enhance their knowledge of CAM in order to maximize patient satisfaction and quality of care.

Use of Complementary and Alternative Medicine (CAM) has dramatically increased globally in the last few decades (Wilkinson et al., 2002; Yom et al., 2008; Zanini et al., 2008). It has been estimated that $70 \%$ of people in the developing world use CAM to resolve health issues (Sheikh et al., 2005). The National Centre for Complementary and Alternative Medicine (NCCAM) defines CAM as "A group of diverse medical and health care systems, practices, and products that are not presently considered to be part of conventional medicine" (NCCAM, 2012, p.1). CAM has developed from the traditional health care practices of different cultures, based on the religious beliefs and philosophies of those cultures (Hilsden, et al. 1999).

In the United States, 91\% of oncology patients use one or more forms of CAM with conventional medicine to manage cancer related symptoms and side effects of cancer treatments (Yates et al., 2005). In European countries, $40 \%$ of oncology patients use some form of CAM; however nurses and physicians are playing a very small part in providing CAM information to them (Molassiotis et al., 2005). In Pakistan, 85\% of cancer patients use CAM (Tovey et al., 2005). The National Institute for Health and Clinical Excellence (NICE) has developed guidelines on supportive and palliative care for adults with cancer (NICE, 2004) and included specific guidelines on CAM. The purpose of these guidelines is to inform patients about accessibility and reliability of information about CAM therapies and CAM therapists. Furthermore, the guidelines are also intended to empower patients and their families to make appropriate decisions regarding CAM. Health professionals need to raise their knowledge about CAM; otherwise it may create a communication gap between them and patients (Rojas-Cooley et al. 2009). This communication gap may harm patients in several ways: patients may use CAM and delay their diagnosis or they may experience side effects of CAM or the interaction of CAM with conventional medications (Furlow, et al. 2008; NCCAM, 2009,). Health care providers need to be knowledgeable about CAM so that they can analyze evidence of effectiveness of those therapies and share this information with patients (Laurenson, et al. 2006). NCCAM (2009) suggested that nurses could initiate conversation with patients regarding CAM, because nurses are direct care providers. It is therefore essential to explore the attitudes, experience and the degree of knowledge of these therapies among oncology nurses.

Studies have shown that $80 \%$ of nurses in Hong Kong were using at least one form of CAM (Xue, et al. 2008) and almost $60 \%$ of oncology nurses had knowledge about CAM (Zanini et al. 2008). Increased interest of the public in CAM has motivated educators to include CAM in nursing and medical curricula in the United States and the United Kingdom (Uzun et al. 2004). In 2002, the University of Washington School of Nursing (UWSON) received a 5-year education grant from the NCCAM to facilitate and evaluate integration of CAM into the nursing curriculum (Booth-laforce, et al. 2010). This CAM integration programme was evaluated through faculty and student surveys about CAM knowledge, attitudes and perceptions. Eighty percent of nursing students indicated that CAM content was included in their courses, with $70 \%$ of the students reporting that their CAM knowledge increased since they were attending UWSON. Fifty percent of students and $54 \%$ of faculty felt that their interest level in CAM had increased to moderate or greater extent. Fifty six percent of the faculty reported that their CAM Knowledge had increased during last three years either to moderate or a greater extent. Students' competencies significantly increase in 2006-2007 than in 2003-2004. Finding showed that this CAM integration 
programme had positive impact on incorporation of CAM content in the curriculum via faculty development (Booth-laforce, et al. 2010).

Several studies have been conducted in different parts of the world to assess nurses' attitudes, knowledge, and experience regarding CAM therapies. Rojas Cooley et al (2009) conducted a descriptive, cross-sectional study involving 850 oncology nurses. The participants' CAM knowledge mean score was $70 \%$ (score range was $0-100$ ). Most of the participants correctly identified conventional medicine but only $50 \%$ correctly identified the term CAM. Overall, participants' attitudes towards CAM were positive. Smith et al (2012) conducted a qualitative study in Taiwan to explore and describe nurses' beliefs, experiences and practices regarding CAM. Data was collected from 11 registered nurses using semi-structured interviews, field notes and memos. Results revealed that the definition of CAM was not clear to nurses in Taiwan and they had limited experience to use CAM in clinical settings. However, the nurses demonstrated great interest in learning more about CAM.

Majeed et al (2007) conducted a study to assess the knowledge, attitude and behavior of medical students in Pakistan and reported that most of the medical students perceived that some therapies were helpful for patients, such as massage (75\%), meditation (70\%), hikmat (64\%), homeopathy (64\%) and acupuncture (63\%). However, the medical students lacked knowledge about the safety and efficacy of these therapies. Despite this, more than $76 \%$ of the medical students felt that CAM should be used in addition to conventional medicine for patients' treatment and $50 \%$ of them suggested that CAM should be incorporated in the medical curriculum (Majeed et al., 2007). In Pakistan, studies have been conducted regarding patients' attitudes, beliefs and practices about CAM and medical students' knowledge, attitudes and behaviors towards CAM. However, no study could be found in Pakistan about nurses' knowledge, experience and attitudes towards CAM particularly among oncology nurses.

\section{Framework}

King's model of transactions was selected as a framework to guide this study. Nursing is defined as an interpersonal process of nurses' action, reaction, interaction and transaction (King, 1981). Transaction can be understood as an activity in which purposeful interaction takes place between a client and a nurse that is directed towards achieving mutually established goals for patients (Alligood et al., 2002).

Figure 1 shows the linkages in the framework of King's theory. The double-sided arrow between nurses and patients indicates that nurses' perception, knowledge, or practice can influence patients and vice versa. If nurses have adequate knowledge, experience and a positive attitude towards CAM, it will enhance interaction between nurses and patients. As a result, patients would share views and concerns about CAM with the nurses. In return, this will provide opportunities for nurses to assist and guide patients towards safe CAM therapies according to patients' needs. This system is open to feedback, as each phase of the activity can influence the perception of patients as well as nurses. The current study focused only on nurses' knowledge, attitude, and experience regarding CAM.

\section{Purpose of the study}

The purpose of the study was to explore the knowledge, experience, and attitudes of oncology nurses with respect to Complementary and Alternative Medicine (CAM) in tertiary care hospitals of Karachi, Pakistan.

\section{Research questions}

Following are the research questions for the oncology nurses:

What degree/level of knowledge do the oncology nurses have about CAM?

How much experience do the oncology nurses have about CAM education?

How much experience do oncology nurses have about the use of CAM ?

What are the attitudes of oncology nurses about the use of CAM by oncology patients?

\section{Methodology of the study}

A survey design was used to determine the knowledge, experiences, and attitudes of oncology nurses towards CAM in various oncology settings. The current study used a Korean questionnaire about CAM knowledge, experience, and attitudes of nurses initially developed by Yom et al (2008), with certain 
modifications after getting the permission for using the tool. Content validity of the tool has been done through literature review and expert review in the Pakistani context. The questionnaire was translated into Urdu and then translated back into English to ensure that the meaning of each item was correct after translating the tool (Polit et al., 2004). The tool was pre-tested on $10 \%$ of oncology nurses before actual data collection. This sample was also included in the final data. On the basis of experience of the pre-test, minor modifications were carried out to ensure that the language would be easy and understandable for the study participants. The questionnaire was divided in 4 sections: (a) Demographic; (b) Knowledge; (c) Experience; and (d) Attitudes.

The study population was oncology registered nurses (RNs) working in inpatient or day care oncology units at 8 locations in Karachi. Study settings include all tertiary care hospitals, which had separate in-patient or day care oncology units. All the oncology RNs working in the oncology units were invited to participate on a voluntary basis. The total population sampling technique was used in the study. All RNs who had at least a three-year diploma in nursing, were working in oncology in-patient or day care units, and who could speak Urdu or English were considered eligible to participate in the study.

The study received ethical clearance from the institutional Ethical Review Committee at the Aga Khan University Hospital. Permission from the individual nursing units of the hospitals was obtained from the medical and nursing directors of the concerned hospitals. Written informed consent was obtained from the participants before collecting data. The participants were informed about their voluntary participation, their right to refuse or withdraw from the study at any time and assured that confidentiality of data would be maintained. The anonymity of the participants was also ensured throughout the study process by using number codes instead of their names on the data collection forms.

Data collection was done from 3rd April 2010, to 30th May 2010. The researcher or the research assistant (RA) personally approached oncology nurses and informed them about the study consent form, the title of the study, its purpose, and the risks and benefits of the study. Participants read the questionnaire, wrote their responses in it and returned that questionnaire back to the researcher or RA as the researcher or RA waited. The researcher rechecked the filled questionnaire for incomplete information or missing data in the fields. The RA was trained for obtaining consent, distributing data forms and checking filled questionnaires for missing or incomplete information. Out of 142 participants, 132 responded to the questionnaire and 10 nurses were not willing to participate in the study, response rate of $92 \%$. The data was double entered in using the Epidata software and then transferred to Statistical Package for the Social Sciences (SPSS) version 16.0, to carry out statistical analysis. Descriptive analyses such as frequencies and percentages were calculated.

\section{Results and discussion}

\section{Demographic profile}

The demographic variables of the participants who participated in this study are illustrated in table 1 . Out of 132 participants, the majority of the oncology nurses (73\%) were females. The age range of participants was between 20-54 years. The participants' mean age was 29 years, and only $9 \%$ were 40 years or older. The majority of oncology nurses (67\%) held only a basic diploma in nursing and none of them had a master's degree in nursing. A few participants had completed other professional nursing courses, including midwifery course $(5 \%)$, oncology certificate course (1\%), and bone marrow transplant (1\%) and critical care short courses (1\%).

Eighty percent of the nurses had oncology experience less than or up to 5 years and $5 \%$ had more than 10 years of experience. Nurses' experience in oncology nursing ranged from 1 week to 16 years. Most of the oncology nurses (86\%) were working as full time employees. Seventy-six percent of the participants were working in private hospitals and $24 \%$ in public hospitals. Moreover, the oncology nurses were working in different clinical settings: $60 \%$ of them were working in the general wards of oncology.

\section{Knowledge about CAM}

Altogether 23 CAM therapies were included in the study. Most of the nurses had heard about multiple CAM therapies. Forty-eight per cent of nurses had sufficient knowledge about prayer (See table 2). Limited Knowledge means the nurses had knowledge about CAM, but they were unable to perform those therapies on patients. Sufficient knowledge means they had enough knowledge about CAM to be able to apply it on 
their patients. More than $90 \%$ of the nurses showed lack of knowledge about cupping, and Moxibustion, Tai chi chuan, Rolfing and Chiropractic. However, Korean nurses reported that $50 \%$ of them had never heard about only two therapies; Rolfing and Chiropractic (Yom et al, 2008). One of the reasons for Pakistani nurses being unaware of many CAM therapies could be that CAM is not included in the formal nursing curriculum of the diploma programme in Pakistan. Previous study also reported that nurses' professional preparation about CAM is fair or poor (Brolinson, et al. 2001). Nurses' knowledge is about different CAM therapies can help them to assist their patients to select CAM that is useful and safe for them (Geller et al, 2005).

A large number of nurses in the current study reported that they had knowledge about prayer (65\%), homeopathy (52\%), massage (50\%) and spiritual healing (49\%). A previous study also reported that $55 \%$ of the nursing students had high or intermediate level of knowledge about massage therapy, and most of them considered massage and prayer as beneficial CAM for patients (Uzun, et al. 2004). The reason for their familiarity with massage in the current and earlier studies could be that back rub, which is taught in nursing school and practiced as a nursing intervention is a type of massage therapy (Uzun et al.). In addition, nurses provide holistic care to patients and for them spirituality is a major aspect of human life. Pakistan, being pre-dominantly a Muslim country, has patients who give greater importance to prayers compared to patients of other countries and nurses would therefore have greater knowledge about prayer as a form of therapy.

\section{Nurses' Experience about CAM}

In total, $25 \%$ nurses had experienced education or training about CAM. Thirty percent of nurses attended conferences on CAM and only $4 \%$ nurses attended CAM certification courses (See table 3). However, Wilkinson et al. (2002) and Zanini et al. (2008) reported that 50 to 70 per cent of the nurses had attended training courses or workshops of CAM. The reason could be that there is no particular course about CAM that exists in the nursing curriculum at the undergraduate programme in Pakistan (Pakistan Nursing Council National Institute of Health, 1998 and The Aga Khan University School of Nursing (AKUSON, 2008). Still AKUSON taught CAM in an adult health nursing course for two hours. Whereas, in Australia there are colleges, which offer CAM courses and diploma programme (McCabe, 2005). The majority of nurses (65\%) experienced seeing patients using CAM and $46 \%$ have seen family members using CAM. Almost $50 \%$ of the nurses used CAM for themselves and their families without having sufficient knowledge or training in this area. Wilkinson et al. (2002) found that $74 \%$ of nurses personally used CAM and $38 \%$ of them applied CAM on patients. The majority of the nurses (71\%) perceived that health status could be enhanced with the use of CAM. This finding is similar to Yom and Lee (2008). Another significant finding is that nearly $50 \%$ of nurses experienced that patients shared their concerns with nurses regarding CAM; which is consistent with Zanini et al. (2008). In addition, 36\% nurses indicated that they had recommended CAM to others. Overall, the nurses reported positive experiences about CAM use in the current study

\section{Nurses' attitude towards CAM}

The majority of nurses (78\%) agreed that they should have the capacity to advise their patients about commonly used CAM methods. The nurses supported CAM education because their lack of knowledge about CAM may decrease their confidence about working in clinical settings. They may believe that education and training about CAM can empower them to work more effectively. In addition, $71 \%$ of the nurses agreed that CAM stimulates the body's natural therapeutic powers. The majority of oncology nurses suggested that CAM should be regulated by the law(73\%), and should be used under the supervision of certified physicians(71\%). This step will make it safe for health professionals to integrate CAM in their clinical practices. Most of the nurses (78\%) agreed that CAM has a positive psychological impact on the patients. The explanation could be that nurses in the current study had used some of CAM therapies for themselves and they might had experienced a good feeling. This particular finding is in contrast with the earlier study done by Zanini et al. where a smaller percentage of nurses in Italy supported this statement. Sixty-one percent of nurses disagreed that it is worthwhile to try CAM before going to the medical professionals (see table 4). Sheikh et al (2005) reported that alternative therapies are considered as the first line of choice for many health problems by people living in the rural areas of Pakistan. However, 
traditional healers may not be professionally trained and certified; patients may end up visiting allopathic experts with worsened health condition (Sheikh et al. 2005). Sixty-five percent of the nurses disagreed that CAM should only be used as a last resort when allopathic treatment did not work. Fifty-six percent of nurses believed that 'CAM could be a supplement to allopathic treatment'. Overall, the nurses showed a positive attitudes towards CAM similar as mentioned in previous studies (Yom et al. 2008; Uzun et al. 2004; Zanini et al. 2008; and Rojas-Cooley et al. 2009 ).

\section{Strengths and limitations of the study}

Overall, the response rate was high (92\%) in the study. It was a challenge to get timely permission from multiple organizations. A number of visits and follow-up meetings were undertaken to complete the procedural formalities for obtaining permission to undertake this study. There were few limitations of the study. Due to the structured nature of the questionnaire, limited knowledge could be collected about the type of training, duration of courses and other factors related to CAM education and training. The findings are limited to selected tertiary care hospitals in Karachi, having separate oncology units. Further studies are recommended to test the generalization of the findings.

\section{Recommendations and Conclusion}

Following recommendations are suggested based on the findings of the study:

Explore the availability of CAM training institutions for health professionals in the country. Introduce certification based CAM courses in the undergraduate and graduate nursing programs. Provide continuing education sessions regarding commonly used CAM for oncology nurses. Study revealed that nurses have positive attitudes towards and experience with, but lack knowledge about CAM. Therefore, it is important to integrate these therapies in nursing curriculum. Findings of the study will provide the foundation for health care agencies to review the nursing curricula and for policy makers to develop guidelines for nurses to use CAM in clinical $\square$ practice.

\section{Conflict of interest: none}

Alligood, M.R., \& Tomey, A.M. (2002). Nursing Theory utilization and Application (2nd ed.). St. Louis: Mosby. Brolinson, P. G., Price, J. H., \& Ditmyer, M., \& Reis, D. (2001). Nurses' perceptions of complementary and alternative medical therapies. Journal of Community Health, 26 (3),175-189.

Booth-Laforce, C., Scott, C.S., Heitkemper, M. M., Cornman, B.J., Lan, M.C., Bond, E.F., et al. (2010). Complementary and Alternative Medicine (CAM) Competencies of Nursing Students and Faculty: Results of Integrating CAM Into the Nursing Curriculum. Journal of Professional Nursing,26(5),293-300.

Furlow, M. L., Patel, D. A., Sen, A., \& Liu, J. R. (2008). Physician and patient attitudes towards complementary and alternative medicine in obstetrics and gynecology. BMC Complementary and Alternative Medicine, 8(35). Geller, S. E., Studee, L., \& Chandra, G. (2005). Knowledge, attitudes, and behaviors of healthcare providers for botanical and dietary supplement use for postmenopausal health. Menopause, 12(1), 49-55.

Hilsden, R. J., \&Verhoef, M. J. (1999). Complementary therapies: evaluating their effectiveness in cancer.

Patient, Education and Counseling, 38, 101-108.

Irfan, H., (2002). Hikmat (Unani Medicine) - Islamic medicine is natural and simple. Retrieved

September 2012 from http://behalal.org/health/hikmat-unani-medicine-islamic- medicine-is-natural-andsimple/

King, I. M. (1981). A theory for nursing: Systems, concepts, process. New York: Delmar publication.

Laurenson, M., MacDonald, J., McCready, T., \& Stimpson, A. (2006). Student nurses' knowledge and attitudes toward CAM therapies. British Journal of Nursing, 15(11), 612-615.

Majeed, K., Mahmmud, H, Khawaja, H. R.,Mansoor, S., Massod,s., \& Khimani, F. (2007). Complementary and Alternative Medicine: Perceptions of medical students from Pakistan. Medical Education,12 (9),1-5. McCabe, P. (2005). Complementary and alternative medicine in Australia: a contemporary overview. Complementary Therapies in Clinical Practice 11, 28-31. 
Molassiotis, A., Fernadez-Ortega, P., Pud, D., Ozden, G., Scott, J.A.,V., Panteli, V., et al. (2005). Use of complementary and alternative medicine in cancer patients: a European survey. Annals of Oncology, 16 (4), 655-663.

National Centre of Complementary and Alternative medicine (2012), what is CAM? Retrieved March, 2012 from, http://nccan.nih.gov/health/whatiscam

National Centre of Complementary and Alternative Medicine (2009). Time to talk: Ask your patients about their use of complementary and alternative medicine. Retrieved March 28, 2013 from http://nccam.nih.gov/timetotalk/forphysicians.htm

National Institute for Health and Clinical Excellence, (2004). Improving Supportive and

Palliative Care for Adults with Cancer. The manual NICE, London. Retrieved from

http://www.nice.org.uk/nicemedia/live/10893/28816/28816.pdf

Pakistan Nursing Council National Institute of Health. (1998). Basic Nursing Curriculum.Islamabad, Pakistan. Polit, D. F., \& Beck, C. T. (2004). Nursing Research:Principles and methods (7th ed.). Piladelphia: Lippincott. Rojas -Cooley, M.T., \& Grant, M. (2009). Complementary and alternative medicine: Oncology nurses' knowledge and attitudes. Oncology Nursing Forum. 36(2), 217-

224.

Sheikh, B. T., \& Hatcher, J. (2005). Complementary and alternative medicine in Pakistan: Prospect and limitation. Evidence - Base Complementary and Alternative Medicine, $2 \quad$ (2), 139-142.

Smith, G.D., \& Wu, S.C. (2012). Nurses' beliefs, experiences and practice regarding complementary and alternative medicine in Taiwan. Journal of Clinical Nursing, 21, 2659-2667.

The Aga Khan University School of Nursing.(2008). Degree program, student handbook.Karachi, Pakistan. Tovey, P.A., Broom, A.F., Chatwin, J., Ahmad, S., \&Hafeez, M. (2005). Use of traditional, complementary and allopathic medicines in Pakistan by cancer patients. Rural and Remote Health, 5(4), 1-9.

Uzun O., \& Tan M. (2004). Nursing students' opinions and knowledge about complementary and alternative medicine therapies. Complementary Therapies in Nursing and Midwifery 10, 239-244.

Wilkinson, J. M., \& Simpson, M.D. ( 2002). Personal and professional use of complementary therapies by nurses in NSW, Australia.Complementry Therapies in Nursing and Midwifery, 8,142-147.

Xue, C.C., Zhang, A.L., Holroyd, E., \&Suen, L. K. (2008). Personal use and professional recommendations of complementary and alternative medicine by Hong Kong registered nurses. Hong Kong Medical Journal,14(2),110-115.

Yates, J. S., Mustain, K.M., Morrow,G.R., Gillies, L. J., Padmanaban et al. (2005). Prevalence of complementary and alternative medicine use in cancer patients.Support Care Cancer, 13, 806-811.

Yom, Y.H., \& Lee, K.E. (2008).A comparison of the knowledge of, experience with and attitudes towards complementary and alternative medicine between nurses and patients in Korea.Journal of Clinical Nursing, 17(19), 2565-2572.

Zanini A., Quattrin, R., Goi, D., Frassinelli, B., Panariti, M., Carpanelli,I., et al. (2008). Italian oncology nurses' knowledge of complementary and alternative therapies: national survey. Journal of Advance Nursing, 62 (4), 451-456. 